
ISSN 2675-6218

\title{
O MAPA MENTAL COMO FERRAMENTA DE ANÁLISE DA COMPREENSÃO DE PROFESSORES SOBRE INTERDISCIPLINARIDADE
}

\section{THE MENTAL MAP AS A TOOL FOR THE ANALYSIS OF TEACHERS 'UNDERSTANDING ABOUT INTERDISCIPLINARITY}

\author{
Terezinha Marisa Ribeiro de Oliveira ${ }^{1}$, Carmem Lúcia Costa Amaral ${ }^{2}$
}

Submetido em: 02/05/2021

e24284

Aprovado em: 22/05/2021

\section{RESUMO}

Este trabalho descreve o resultado de uma pesquisa que teve como objetivo investigar os mapas mentais como instrumento de análise da compreensão de professores sobre interdisciplinaridade após a participação de uma oficina envolvendo projetos interdisciplinares em Educação Ambiental. A oficina foi desenvolvida durante as reuniões de Atividades de Trabalho Pedagógico Coletivo (ATPC) e contou com onze encontros. A pesquisa teve uma abordagem qualitativa e como procedimento metodológico a pesquisa-ação. Participaram dessa oficina 15 professores das diversas áreas do conhecimento de uma escola estadual no interior de São Paulo. Os mapas mentais foram analisados a partir dos critérios propostos por Buzan (2019). Nesse trabalho apresentamos a análise de quatro mapas mentais envolvendo a interdisciplinaridade, projetos interdisciplinares e projetos interdisciplinares em educação ambiental. Os resultados observados evidenciaram que eles podem não só serem utilizados para a análise de compreensão de um determinado tema, no nosso caso, a interdisciplinaridade e os projetos interdisciplinares na educação ambiental, mas também a sua construção proporcionou uma nova ferramenta para os professores utilizarem em suas aulas ou mesmo para estudarem, uma vez que para sua construção retiraram do texto as ideias principais e as colocaram na forma de palavras chave, desenvolvendo assim, a habilidade de abstração e auxiliou na visão sistêmica da interdisciplinaridade.

PALAVRAS-CHAVE: Interdisciplinaridade. Aperfeiçoamento de Professores. Apoio Pedagógico.

\begin{abstract}
This work describes the result of a research that investigated mind maps as an instrument for the analysis of teachers' understanding of interdisciplinarity after the participation of a workshop' interdisciplinary projects in Environmental Education. The workshop was developed during the Collective Pedagogical Work Activities (CPWA) meetings and had eleven meetings. The research had a qualitative approach and as a methodological procedure the action-research. Fifteen teachers from different areas of knowledge from a state school in the interior of São Paulo participated in this workshop. The mind maps were analyzed based on the criteria proposed by Buzan (2019). In this work we present the analysis of four mind maps involving interdisciplinarity, interdisciplinary projects and interdisciplinary projects in environmental education. The observed results showed that they can not only be used for the analysis of understanding of a given theme, in this case, interdisciplinarity and interdisciplinary projects in environmental education, but also its construction provided a new tool for teachers to use in their classes or even to study, since for its construction they removed the main ideas from the text and put them in the form of keywords, thus developing the ability to abstraction and helped in the systemic view of interdisciplinarity.
\end{abstract}

KEYWORDS: Interdisciplinarity. Teacher Improvement. Pedagogical Support

\footnotetext{
${ }^{1}$ Doutoranda na Universidade Cruzeiro do Sul em Ensino de Ciências e Matemática. Mestrado em Ensino de Ciências (área de concentração Ensino de Ciências e Matemática), na Universidade Cruzeiro do Sul.

2 Doutora em Química Orgânica pela Universidade de São Paulo (USP). Professora do Programa de Pósgraduação Stricto Sensu em Ensino de Ciências e Matemática da Universidade Cruzeiro do Sul.
} 


\section{RECIMA21 - REVISTA CIENTÍFICA MULTIDISCIPLINAR ISSN 2675-6218}

O MAPA MENTAL COMO FERRAMENTA DE ANÁLISE DA COMPREENSÃO DE PROFESSORES SOBRE INTERDISCIPLINARIDADE Terezinha Marisa Ribeiro de Oliveira, Carmem Lúcia Costa Amaral

INTRODUÇÃO

Como professoras há alguns anos temos observado que o desenvolvimento de projetos interdisciplinares no ambiente escolar, apesar de não ser um assunto novo, muitas vezes não é discutido pela gestão escolar com os docentes, uma vez que esta pressupõe que a temática já está incorporada aos saberes que acompanham o profissional, pois os documentos como os Parâmetros Curriculares Nacionais (PCN) e mais recentemente a Base Nacional Comum Curricular (BNCC) trazem essa proposta. Dessa forma, a gestão não leva em consideração que muitas vezes esses projetos interdisciplinares só ficam como propostas nos documentos, pois o professor não se dá conta da importância da interdisciplinaridade e como consequência não a desenvolve com seus pares. Assim, torna-se importante discutir essa temática com os professores.

Pensando em auxiliar um grupo de professores de uma escola paulista a compreenderem a importância da interdisciplinaridade e do desenvolvimento de projetos interdisciplinares na escola, planejamos e desenvolvemos uma oficina que ocorreu em onze encontros de ATPC. Durante esses encontros um dos professores participantes da oficina indagou se conhecíamos os mapas mentais. Ao responder que sim, esse professor, juntamente com os outros que indagaram que não conheciam essa ferramenta, solicitou que o utilizasse na oficina, pois gostaria de conhecê-lo para se possível utilizá-lo depois com seus alunos.

Com base na solicitação dos professores, indagamos: os mapas mentais podem ser utilizados como ferramenta de análise da compreensão dos professores sobre a temática desenvolvida na oficina? Assim, neste artigo, descrevemos o resultado de uma pesquisa que teve como objetivo geral investigar os mapas mentais como instrumento de análise da compreensão de professores sobre interdisciplinaridade após a participação em uma oficina envolvendo essa temática.

\section{Os Mapas Mentais}

Os Mapas Mentais originaram-se em meados da década de 1970 e o seu criador, Tony Buzan (2019), os classificou como sendo uma ferramenta que armazena, organiza e prioriza informações. São construídos, em geral no papel, imitando a forma de um neurônio, pois para seu criador, essa forma estimula o cérebro a trabalhar com mais rapidez e eficiência. Essa forma, segundo Zandomeneghi, Gobbo e Bonfiglio (2015) espelha de maneira não linear como funciona o cérebro, uma vez que não depende de texto escrito, mas de linhas, símbolos, palavras-chave, cores e imagens.

Essa forma não linear de organização de uma informação favorece a memorização, a criatividade, a organização de ideias e possibilita a análise de dados. Para Buzan (2019), esta ferramenta apresenta várias vantagens sobre as anotações convencionais que utilizamos, por 


\section{RECIMA21 - REVISTA CIENTÍFICA MULTIDISCIPLINAR ISSN 2675-6218}

O MAPA MENTAL COMO FERRAMENTA DE ANÁLISE DA COMPREENSÃO DE PROFESSORES SOBRE INTERDISCIPLINARIDADE Terezinha Marisa Ribeiro de Oliveira, Carmem Lúcia Costa Amaral

exemplo, durante uma aula. O Quadro 2 apresenta as características fundamentais entre as duas formas de anotações.

Quadro 2 - Anotações convencionais versus mapa mental

\begin{tabular}{|c|c|}
\hline Anotações convencionais & Anotações utilizando os mapas mentais \\
\hline Lineares & Multifacetado \\
\hline Monocromáticas & Colorido \\
\hline Baseadas em palavras & Palavras e imagens \\
\hline Lógica das listas & Lógica das associações \\
\hline Sequenciais & Multidimensional \\
\hline Restritivas & Imaginativo \\
\hline Desorganizadas & Analítico \\
\hline
\end{tabular}

Fonte: Buzan (2019, p. 20).

Para esse autor, as características das anotações convencionais citadas acima não estimulam o cérebro e como consequência diminui a motivação no processo de aprender. O mapa mental, para Hermann e Bovo (2005), Vilela (2012) e Buzan (2019) é uma ferramenta que pode ser utilizada por qualquer pessoa, tanto criança quanto um adulto, desde que seja alfabetizada.

Para Buzan (2019), é uma ferramenta holística e que, ao ser visualizado em um papel, representa um diagrama colorido que auxilia a capturar informações, usando o córtex cerebral ao ativar um pensamento que utiliza os hemisférios esquerdo (lógico) e direito (criativo). O autor considera que um mapa mental deve ter três características principais:

$\checkmark$ Imagem central, que tem por finalidade resumir a temática principal.

$\checkmark$ Ramificações grossas que se espalham a partir da imagem central. Tais ramificações estão relacionadas com o tema central e devem ser de cores diferentes, dividindo-se em sub-ramificações ("galhos").

$\checkmark$ Uma única imagem ou palavra-chave em cada ramificação.

Hermann e Bovo (2005) afirmam que na elaboração dos mapas mentais utiliza-se a linguagem verbal conjuntamente com ilustrações, ou mesmo símbolos, cores, flechas e esquemas, com a intenção de aumentar os estímulos cognitivos que muitas vezes não se consegue alcançar com a educação tradicional. Até mesmo a mudança na posição do papel é considerada um importante recurso na aprendizagem.

O uso de mapas mentais segundo Vilela (2012), possui diferentes finalidades como extrair o que é substancial do conteúdo, ou seja, o que realmente tem importância; auxiliar na organização das ideias, que muitas vezes não estão tão claras, facilitando a compreensão e 


\section{RECIMA21 - REVISTA CIENTÍFICA MULTIDISCIPLINAR ISSN 2675-6218}

O MAPA MENTAL COMO FERRAMENTA DE ANÁLISE DA COMPREENSÃO DE PROFESSORES SOBRE INTERDISCIPLINARIDADE Terezinha Marisa Ribeiro de Oliveira, Carmem Lúcia Costa Amaral

auxiliar no processo de revisão. Além disso, podem ser utilizados em grupos colaborativos para partilhar conceitos e críticas.

Para sua construção é preciso dominar a técnica para não cair em erros recorrentes, como criar diagramas, mapa conceitual, um gráfico de explosão solar ou até mesmo um fluxograma (BUZAN, 2019). Assim, para não cair em erros recorrentes na construção dessa ferramenta, o autor enumera as dez leis do mapeamento mental:

1. Utilizar uma folha grande na horizontal permitindo a criação das ramificações e das subramificações da temática principal.

2. Desenhar uma imagem no centro do papel ou escrever com pelo menos três cores a representação da sua temática.

3. Usar imagens ou símbolos em todo o Mapa Mental.

4. Palavras-chaves em maiúsculas.

5. Inserir a palavra ou a imagem ao adequar a sua respectiva ramificação.

6. As ramificações que saem do centro devem ser mais grossas e com linhas curvas e finas à medida que se tornam sub-ramificações.

7. O comprimento das ramificações deve acompanhar o tamanho das palavras ou imagens.

8. É importante o uso de cores em cada ramificação do Mapa Mental.

9. Usar sublinhados, setas e linhas de conexão.

10. Posicionar as ramificações cuidadosamente e com clareza.

Os mapas mentais podem apresentar diferentes concepções para um mesmo conteúdo, pois essa construção depende da estrutura mental, do conhecimento e de como cada pessoa o constrói de acordo com as informações disponibilizadas sobre a temática em questão (KEIDANN, 2013). Nesse trabalho os mapas mentais foram utilizados como uma ferramenta de análise da compreensão de um grupo de professores sobre a interdisciplinaridade e o desenvolvimento de projetos interdisciplinares envolvendo a Educação Ambiental.

A interdisciplinaridade não é um assunto novo, mas é um tema recorrente que engaja tanto defensores quanto opositores em discussões acaloradas, e que por estar frequentemente em pauta, suscita debates sempre atuais. Seu conceito, segundo Zidan (2012), chegou as escolas brasileiras pelo Ministério da Educação na década de 1990 com a promulgação dos PCN para os Ensinos Fundamental e Médio, porém como descreve a autora, seus preceitos não foram incorporados à ação docente, seja por problemas estruturais organizacionais ou mesmo por imposição de barreiras em sua aplicabilidade, que causou, de acordo com Luquetti e Souza (2016), inúmeras implicações pedagógicas, ao gerar riscos e conflitos.

De acordo com os PCN a interdisciplinaridade escolar ao utilizar os conhecimentos das diversas áreas na resolução de um problema concreto ou na compreensão de um determinado 


\section{RECIMA21 - REVISTA CIENTÍFICA MULTIDISCIPLINAR ISSN 2675-6218}

O MAPA MENTAL COMO FERRAMENTA DE ANÁLISE DA COMPREENSÃO DE PROFESSORES SOBRE INTERDISCIPLINARIDADE Terezinha Marisa Ribeiro de Oliveira, Carmem Lúcia Costa Amaral

fenômeno sob diferentes pontos de vista, apresenta uma função instrumental, por meio da qual um saber diretamente útil e utilizável passa a responder às questões e aos problemas sociais contemporâneos (BRASIL, 2000).

A interdisciplinaridade incorporou-se ao contexto escolar por meio de projetos que, de acordo com Evangelista, Colares e Ferreira (2009), é a menor unidade do planejamento, com objetivos e metas. Para seu desenvolvimento é preciso que se tenha um problema ou interesse individual, de uma instituição ou de um grupo. Segundo Hernández (2010) um projeto deve contemplar um eixo problematizador que ofereça análises, interpretações e críticas com diferentes visões, com diferentes formas de aprender e ensinar e o professor deve aproximar os problemas das disciplinas e dos saberes.

Essas situações evidenciam a importância de se desenvolver, individualmente ou com seus pares, a cultura de buscar orientações para auxiliar na predileção de materiais ou mesmo métodos diferenciados de inserir projetos que atendam a interesses individuais com ações de alcance comunitário ou social (BRASIL, 2002).

Um projeto é importante para professores e alunos, pois auxilia na construção do conhecimento e na aceitação de responsabilidades e assim fundamenta a interdisciplinaridade, ao valorizar a ação, a pesquisa e as conexões em sua totalidade com a natureza. Para Evangelista, Colares e Ferreira (2009, p. 4), "desenvolver projetos interdisciplinares é buscar o renascer da educação holística" e a visão holística na educação auxilia, segundo Behrens (2006), a superar a fragmentação do conhecimento disciplinar.

Desenvolver projetos interdisciplinares envolvendo EA é uma das estratégias de articulação entre o meio ambiente e a construção de conhecimento, pois oferece a integração dos diferentes campos disciplinares. Como descreve Lindner (2012) as questões que dizem respeito ao meio ambiente, quando discutidas a partir da interdisciplinaridade, podem ser de fato vivenciadas e debatidas de maneira crítica.

Para Tristão (2012), a EA tem, na interdisciplinaridade, um importante aliado para romper com a fragmentação do conhecimento, que oferece uma organização, mesmo que as disciplinas tenham seu formato aberto ou fechado devido a um currículo engaiolado sem a articulação entre as áreas. Para isso é importante que a EA seja discutida no ATPC, pois ao incidir sobre o individual e o coletivo a escola se compromete com uma mudança quanto às questões ambientais.

\section{CAMINHO METODOLÓGICO}

A abordagem metodológica utilizada nesse trabalho foi de uma pesquisa qualitativa do tipo descritiva. A pesquisa qualitativa de acordo com Bogdan e Biklen (2010, p.49) "exige que o mundo seja examinado com a ideia de que nada é trivial, que tudo tem potencial para constituir uma pista que nos permita estabelecer uma compreensão mais esclarecedora do nosso objeto de estudo". 

ISSN 2675-6218

Para o desenvolvimento dessa pesquisa desenvolvemos uma oficina com a participação de 15 professores das áreas de Códigos de Linguagens (Língua Portuguesa, Inglês, Arte e Educação Física); Ciências da Natureza (Ciências, Química, Física e Biologia); Ciências Humanas (História, Geografia, Filosofia e Sociologia) e Matemática, em uma escola estadual de São Paulo. Para preservar suas identidades, esses professores serão denominados nesse artigo como P1, $P 2, \ldots . . P 15$.

A oficina ocorreu em sete encontros de ATPC, com a duração de 50 minutos cada. Devido a esse curto tempo de ATPC optamos em discutir e apresentar as definições e procedimentos de construção de projetos interdisciplinares e o conceito de interdisciplinaridade, uma vez que sem esse conhecimento não é possível desenvolver projetos interdisciplinares.

Inicialmente discutimos os conceitos de interdisciplinaridade apresentados pelo PCN (BRASIL, 2000), PCN+ (BRASIL, 2002), e por Fazenda (2008) e González-Gaudiano (2006) e para os projetos interdisciplinares o artigo de Evangelista, Colares e Ferreira (2009). No primeiro encontro foi combinado com os professores que os textos de cada encontro posterior seriam disponibilizados com antecedência. O quadro 1 mostra as atividades de cada encontro.

Quadro 1 - As atividades realizadas em cada encontro da oficina.

\begin{tabular}{|c|l|}
\hline Encontros & \multicolumn{1}{|c|}{ Atividades } \\
\hline 1 e 2 & $\begin{array}{l}\text { Apresentação da pesquisa e do planejamento da oficina e assinatura do } \\
\text { TCLE. } \\
\text { Discutindo o conceito de interdisciplinaridade a partir do PCN e PCN+ }\end{array}$ \\
\hline 3 e 4 & $\begin{array}{l}\text { Discutindo o texto: A aquisição de uma formação interdisciplinar de } \\
\text { professores (FAZENDA, 2008) }\end{array}$ \\
\hline 5 e 6 & $\begin{array}{l}\text { Discutindo o texto: Projetos educativos interdisciplinares na prática docente } \\
\text { (EVANGELISTA; COLARES; FERREIRA, 2009). }\end{array}$ \\
\hline 7 e 8 & $\begin{array}{l}\text { Discutindo o texto: Interdisciplinaridade e educação ambiental: explorando } \\
\text { novos territórios epistêmicos (GONZÁLEZ-GAUDIANO). }\end{array}$ \\
\hline 9 & $\begin{array}{l}\text { Apresentação dos mapas mentais, sua teoria e os critérios de sua } \\
\text { elaboração segundo Buzan. } \\
\text { Apresentação do disponível } \\
\text { https://www.youtube.com/watch?v=Hahyn7vw8PY }\end{array}$ \\
\hline 10 & $\begin{array}{l}\text { Elaboração dos mapas mentais pelos professores. } \\
\text { Aiscussão dos mapas mentais elaborados pelos professores. }\end{array}$ \\
\hline 11 & emálise da oficina por escrito \\
\hline
\end{tabular}

Fonte: As autoras

Durante as leituras dos artigos, os professores foram selecionando as palavras chaves que para eles representavam a interdisciplinaridade e os projetos interdisciplinares. Como critério de avaliação da compreensão dos professores sobre os tópicos discutidos na oficina solicitamos a construção de mapas mentais e os analisamos levando em consideração as ideias de 

ISSN 2675-6218

O MAPA MENTAL COMO FERRAMENTA DE ANÁLISE DA COMPREENSÃO DE PROFESSORES SOBRE INTERDISCIPLINARIDADE Terezinha Marisa Ribeiro de Oliveira, Carmem Lúcia Costa Amaral

organização básica de um mapa mental proposto por Buzan (2019). Essa organização requer que o mapa mental seja construído de forma a apresentar estrutura, classificação (como as palavraschave se relacionam) e definições (o que significa para o professor suas palavras-chave).

Como dizem Hermann e Bovo (2005), o mapa mental é ótimo para fazer anotações nãolineares de maneira simples e eficaz, e tem como um dos seus objetivos gerenciar informações, além de estimular a criatividade e a memorização.

\section{RESULTADOS E DISCUSSÃO}

\section{Perfil dos professores que participaram da oficina}

Antes de iniciar essa pesquisa procurou-se conhecer o perfil dos professores que participaram da oficina, pois conhecê-los era essencial para entender suas práticas, seu cotidiano de trabalho e suas percepções.

Quanto ao gênero, 4 (quatro) são do sexo masculino e 11 (onze) são do sexo feminino. Esses dados estão próximos do percentual nacional, pois ainda de acordo com o censo escolar de 2020, a participação de mulheres na Educação Básica era de 77,3 \% (BRASIL, 2021).

Quanto ao tempo de magistério, a maioria (10) estava entre 7 e 25 anos. No quadro 1 apresentamos o tempo de magistério desses professores e as fases dos docentes da escola de acordo com o ciclo de vida adaptado de Huberman (2013).

Quadro 1 - Ciclo de vida dos professores, anos de carreira e o número de professores em cada faixa.

\begin{tabular}{|c|c|c|c|}
\hline $\begin{array}{c}\text { FASES/TEMAS DA CARREIRA } \\
\text { Ciclo de vida de acordo com Huberman }\end{array}$ & $\begin{array}{c}\text { Anos de } \\
\text { Carreira }\end{array}$ & $\begin{array}{c}\mathrm{N}^{\circ} \text { de } \\
\text { Docentes }\end{array}$ & Docentes \\
\hline $\begin{array}{c}\text { ENTRADA/TATEAMENTO } \\
\text { ESTABILIZAÇÃO }\end{array}$ & $\begin{array}{l}\text { de } 1 \text { a } 3 \\
\text { de } 4 \text { a } 6\end{array}$ & 0 & \\
\hline $\begin{array}{c}\text { DIVERSIFICAÇÃO } \\
\text { QUESTIONAMENTO }\end{array}$ & de 7 a 25 & 10 & $\begin{array}{c}\text { P1, P4, P5, P6, } \\
\text { P7, P9, P10, } \\
\text { P11, P13, P15 }\end{array}$ \\
\hline $\begin{array}{c}\text { SERENIDADE } \\
\text { DISTANCIAMENTO } \rightarrow \\
\text { AFETIVO/CONSERVANTISMO }\end{array}$ & de 26 a 35 & 5 & $\begin{array}{c}\text { P2, P3, P8, P12, } \\
\text { P14 }\end{array}$ \\
\hline DESENVESTIMENTO & de 35 a 40 & 0 & \\
\hline
\end{tabular}

Fonte: Autoras

A partir do quadro 1 observamos que a maioria dos professores estão na fase de diversificação/questionamento, seguida da fase de serenidade. Segundo Huberman (2013), na fase de diversificação/questionamento o professor procura uma diversificação do seu método de ensinar ou questiona-se quanto ao seu fazer pedagógico. Muitas vezes, o docente tende a se autoquestionar sem saber ao certo o porquê, acarretado por uma apatia ou desencanto. Na fase 


\section{RECIMA21 - REVISTA CIENTÍFICA MULTIDISCIPLINAR ISSN 2675-6218}

O MAPA MENTAL COMO FERRAMENTA DE ANÁLISE DA COMPREENSÃO DE PROFESSORES SOBRE INTERDISCIPLINARIDADE Terezinha Marisa Ribeiro de Oliveira, Carmem Lúcia Costa Amaral

de serenidade o docente tem um perfil menos vulnerável, com pouco investimento e menos ambição na careira.

A partir das fases da carreira apresentadas por Huberman (2013), podemos inferir que ao participarem da oficina os professores estavam buscando uma diversificação de sua prática em relação as questões ambientais, uma vez que ele está em uma fase de questionamento sobre o seu trabalho em sala de aula.

Com relação a formação inicial, a maioria (94\%) concluiu sua graduação em universidade particular. Porém, todos são habilitados para a função que desempenham, isto é, a formação é condizente com a atividade docente. Na escola em que esses professores lecionam todos possuem nível superior completo dentro da área de atuação. Assim, ela atende uma das metas do Plano Nacional da Educação que é ter todos os docentes da educação básica com formação específica de nível superior, obtida em curso de licenciatura na área de conhecimento em que atuam (BRASIL, 2014).

\section{A oficina e os mapas mentais}

Uma vez que o objetivo da oficina foi discutir a importância de projetos interdisciplinares envolvendo a EA como estratégia para diminuir a sua fragmentação, planejamos e desenvolvemos uma oficina discutindo inicialmente os conceitos de interdisciplinaridade e sobre como desenvolver projetos na escola, particularmente, projetos interdisciplinares.

Embora as discussões sobre EA, projetos e interdisciplinaridade não sejam novas no ambiente escolar, pois as reuniões de ATPC abordam esses assuntos frequentemente, evidenciou-se que ficam só nas discussões, ou seja, não acontecem no ambiente escolar. Isso reafirma a opinião de Zidan (2012), que diz que mesmo com a inserção dos PCN na década de 1990, que oficializou a prática interdisciplinar, esta não foi incorporada à ação docente por problemas estruturais organizacionais ou mesmo por imposição de barreiras em sua aplicabilidade. Reforçando essa ideia P8 disse:

É extremamente importante concretizar os projetos interdisciplinares, por meio dessa oficina observamos a necessidade de se trabalhar esse tema (P8).

Como forma de avaliação do entendimento dos professores sobre o que estava sendo discutido nos encontros utilizamos os mapas mentais. Como parte da dinâmica da oficina cada professor construiu individualmente seu mapa escolhendo os conceitos estudados.

Para Behrens (2006) e Evangelista, Colares e Ferreira (2009) a interdisciplinaridade tem uma concepção holística, assim como os mapas mentais segundo Buzan (2019). Essa concepção holística, de acordo com Behrens (2006), auxilia na superação da fragmentação do conhecimento disciplinar ao favorecer as interações entre professores, alunos e a comunidade. 

ISSN 2675-6218

A importância de conhecer ferramentas diferenciadas como os mapas mentais foi reforçada por P8 que complementou a fala acima:

As estratégias utilizadas nos mapas sem dúvida esclareceram e fortaleceram essa necessidade (P8).

Essa fala indica que a ferramenta, como estratégia pedagógica, colaborou com o entendimento da temática da oficina. Como descrevem Hermann e Bovo (2005) a utilização da linguagem verbal, em conjunto com ilustrações, símbolos, cores, flechas e esquemas, modifica o formato tradicional que os professores estão acostumados ou mesmo evita o que Luquetti e Souza (2016) alertam sobre a interdisciplinaridade gerar inúmeras implicações pedagógicas e muitos conflitos, uma vez que considera as relações de cada saber, o que possibilita a necessidade de um trabalho em equipe.

De uma forma geral, ao analisar os mapas mentais observamos as características enunciadas por Buzan (2019) para identificar um bom mapa mental, ou seja, os professores conseguiram representar e atender a esses critérios, que envolvem: ter uma temática central, ter ramificações grossas que partem do centro, com diferentes cores e sub-ramificações com uma imagem ou palavra-chave. A seguir apresentamos quatro mapas mentais construídos pelos professores no encontro 10: um envolvendo projetos interdisciplinares, 2 envolvendo a interdisciplinaridade e um envolvendo os projetos interdisciplinares em EA. Esses mapas foram escolhidos de forma aleatória. A figura 1 apresenta o mapa mental construído por P7.

Figura 1 - Mapa Mental sobre projetos interdisciplinares (P7).

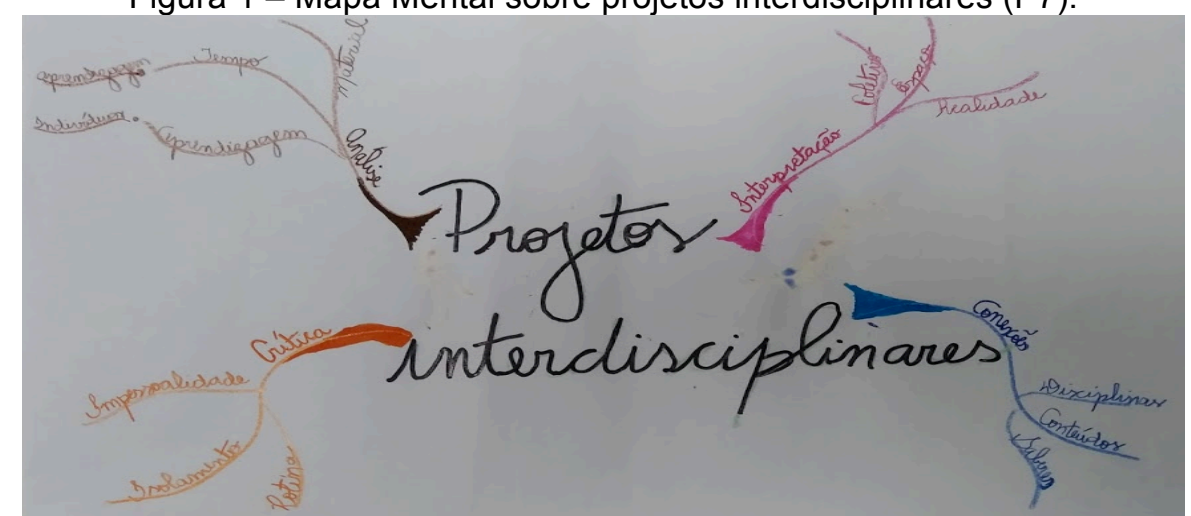

Fonte: Autoras

Como pode ser observado, esse mapa apresenta quatro palavras-chave nas ramificações que saem do centro e as suas derivações nas sub-ramificações: interpretação (espaço, coletivo e realidade), conexões (disciplinas, conteúdos e saberes), crítica (impessoalidade, isolamento e rotina) e análise (material, tempo-aprendizagem, aprendizagem-indivíduos). Interpretando esse mapa podemos perceber que para P7 projetos interdisciplinares são conectados com as disciplinas, com o conteúdo e com os saberes. É uma crítica a impessoalidade, ao isolamento 


\section{RECIMA21 - REVISTA CIENTÍFICA MULTIDISCIPLINAR ISSN 2675-6218}

O MAPA MENTAL COMO FERRAMENTA DE ANÁLISE DA COMPREENSÃO DE PROFESSORES SOBRE INTERDISCIPLINARIDADE Terezinha Marisa Ribeiro de Oliveira, Carmem Lúcia Costa Amaral

porque o professor não trabalha sozinho e a rotina da sala de aula. Com os projetos interdisciplinares, de acordo com seu mapa, há a interpretação coletiva da realidade em um determinado espaço de tempo. Ele permite a análise da aprendizagem dos indivíduos, o tempo de aprendizagem e analisa se o material que o professor está usando é adequado. Assim, ao analisar esse mapa mental concluímos que P7 apresenta uma interpretação sobre projetos interdisciplinares de acordo com Hernández (2010) que é contemplar um eixo problematizador que ofereça análises, interpretações e críticas com diferentes visões, com diferentes formas de ensinar e o professor deve aproximar os problemas das disciplinas e dos saberes. A figura 2 apresenta o mapa mental construído por P13.

Figura 2 - Mapa Mental sobre interdisciplinaridade (P13).

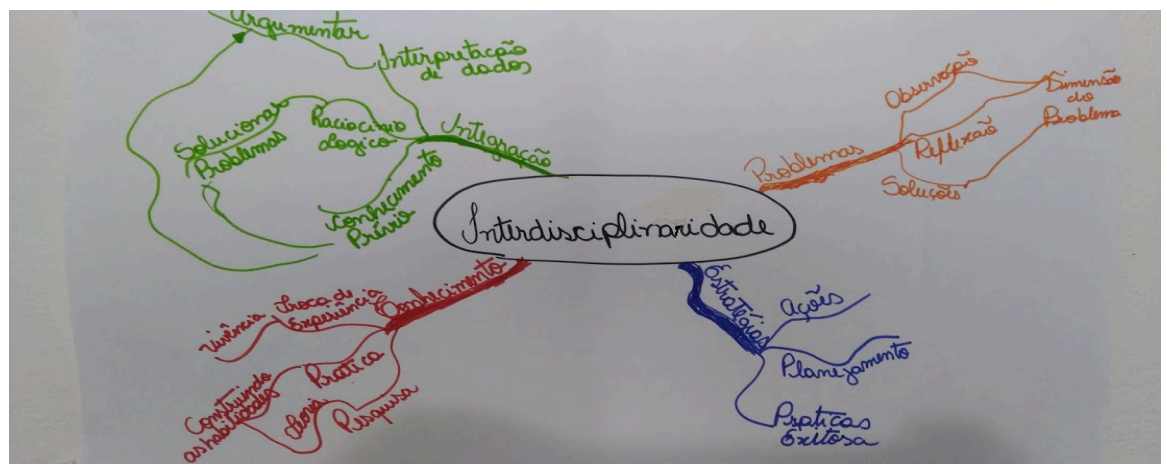

Fonte: Autoras

Esse mapa apresenta quatro palavras-chave nas ramificações que saem do centro e as suas derivações nas sub-ramificações: integração (conhecimento prévio, raciocínio lógico, interpretação de dados, solucionar problemas e argumentar), conhecimento (troca de experiências, práticas, pesquisa), estratégias (ações, planejamento, práticas exitosas) e problemas (observações, reflexão, soluções). Para P13 a interdisciplinaridade permite a integração de conhecimentos prévios com o raciocínio lógico e a interpretação de dados e a partir desses dois últimos, é possível solucionar um problema. Para esse professor, a interdisciplinaridade leva a construção do conhecimento a partir da troca de experiência, da prática e da pesquisa. Essas últimas constroem habilidades e a troca de experiência está associada com a sua vivência. Para sua construção deve-se partir de estratégias que estão ligadas as ações, planejamento e práticas exitosas. A interdisciplinaridade possibilita a resolução de um problema a partir da observação e da reflexão de acordo com a dimensão do problema.

Nesses dois mapas mentais, os docentes realizaram uma crítica no formato centrado na impessoalidade, no isolamento e na rotina que muitas vezes é encontrado no contexto escolar. P7 


\section{RECIMA21 - REVISTA CIENTÍFICA MULTIDISCIPLINAR ISSN 2675-6218}

O MAPA MENTAL COMO FERRAMENTA DE ANÁLISE DA COMPREENSÃO DE PROFESSORES SOBRE INTERDISCIPLINARIDADE Terezinha Marisa Ribeiro de Oliveira, Carmem Lúcia Costa Amaral

coloca a crítica ao isolamento proporcionado muitas vezes pelo formato disciplinar que rege o ambiente escolar e P13 coloca a importância de unir o conhecimento partilhado entre os pares, ao colocar a inter-relação com a troca de experiências e as vivências, valorizando o coletivo. A figura 3 apresenta o mapa mental construído por P11.

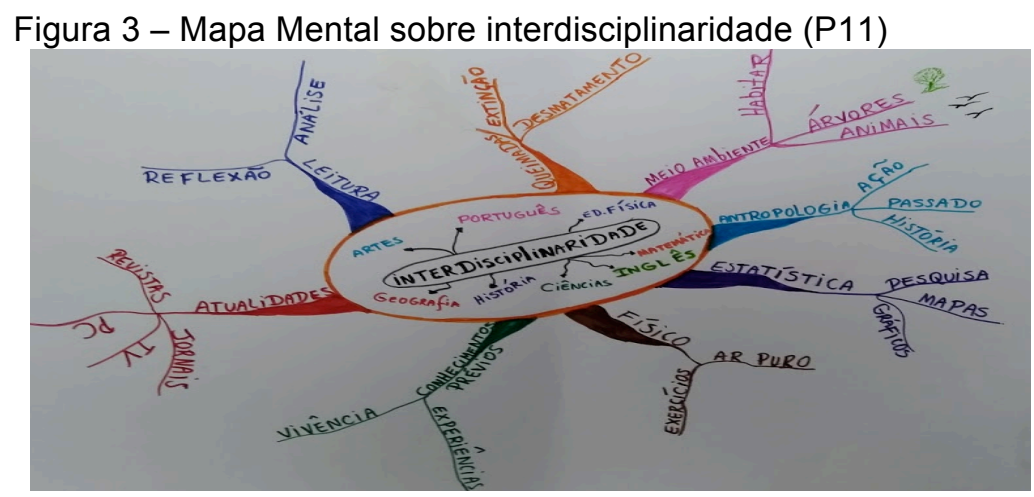

Fonte: Autoras

P11 também construiu seu mapa mental sobre interdisciplinaridade. Entretanto, no seu mapa ela mostrou o que a geografia, que é sua disciplina, pode trabalhar de forma interdisciplinar com as outras disciplinas do currículo do Ensino Fundamental Anos Finais. Por exemplo, ela pode trabalhar a matemática dentro da sua disciplina utilizando a estatística por meio de pesquisa, mapas e gráficos. Pode trabalhar com a disciplina de português a partir da leitura que auxilia na análise e reflexão e com a antropologia discutindo as ações do ser humano na história de seu passado (origem) e suas ações no planeta.

De acordo com o $\mathrm{PCN}+$, ao unir as diferentes disciplinas em um trabalho diversificado para garantir a junção de diferentes assuntos que se inter-relacionam, garante o desenvolvimento de competências e habilidades por meio da pesquisa, da reflexão e da crítica, entendendo as diferentes linguagens, que desta forma permitem diferentes interpretações (BRASIL, 2002). P10 escolheu a Educação Ambiental como tema para desenvolver a interdisciplinaridade dentro de algumas disciplinas escolares como química, geografia, matemática e artes. Quanto a interdisciplinaridade da Educação Ambiental, a figura 4 mostra o mapa mental construído por P10. 


\section{RECIMA21 - REVISTA CIENTÍFICA MULTIDISCIPLINAR ISSN 2675-6218}

O MAPA MENTAL COMO FERRAMENTA DE ANÁLISE DA COMPREENSÃO DE PROFESSORES SOBRE INTERDISCIPLINARIDADE Terezinha Marisa Ribeiro de Oliveira, Carmem Lúcia Costa Amaral

Figura 4 - Mapa Mental com um eixo integrador sendo a EA (P10)

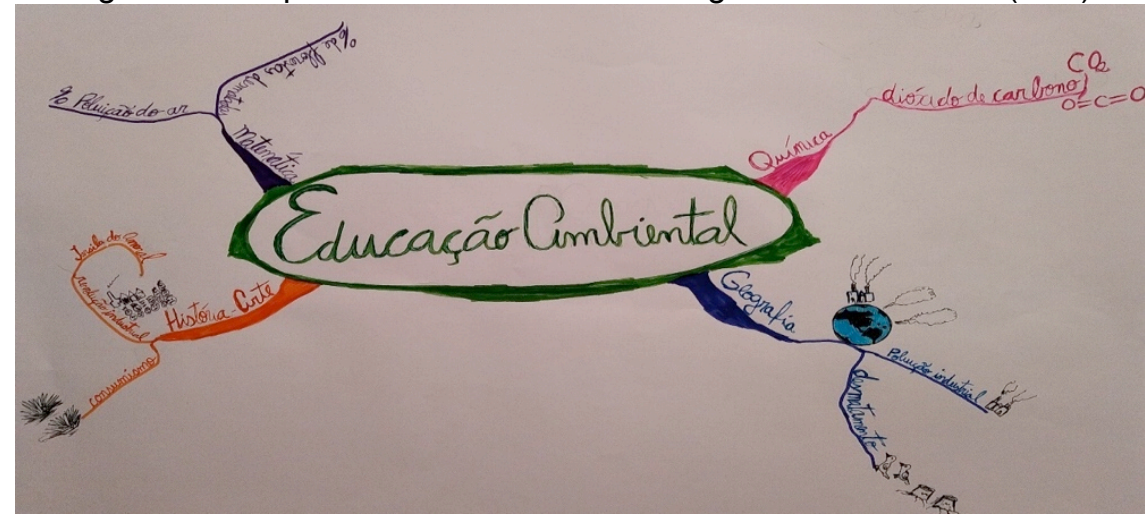

Fonte: Autoras

Em seu mapa P10 faz uma crítica ao sistema capitalista, que leva a destruição do planeta. P10 reconhece o caráter interdisciplinar e transversal da Educação Ambiental, reforçando a ideia de Vilela (2012), que o uso de mapas mentais incide em diferentes finalidades e uma delas é extrair o que é substancial do conteúdo, ou seja, o que realmente tem importância, ao organizar as ideias, no processo de revisão de diferentes textos.

Entretanto, ao organizar as ideias, os mapas mentais possibilitam estabelecer relações multifacetadas, como no caso da Educação Ambiental apresentada por P10 que coloca as diferentes áreas com o seu próprio modo de interpretar a problemática mundial do consumismo, do desmatamento e da poluição do planeta.

A figura 5 apresenta um recorte do mapa mental de P10 para mostrar o eixo integrador da EA (Figura 4).

Figura 5 - Recorte do Mapa Mental com a EA como um eixo integrador (P10).

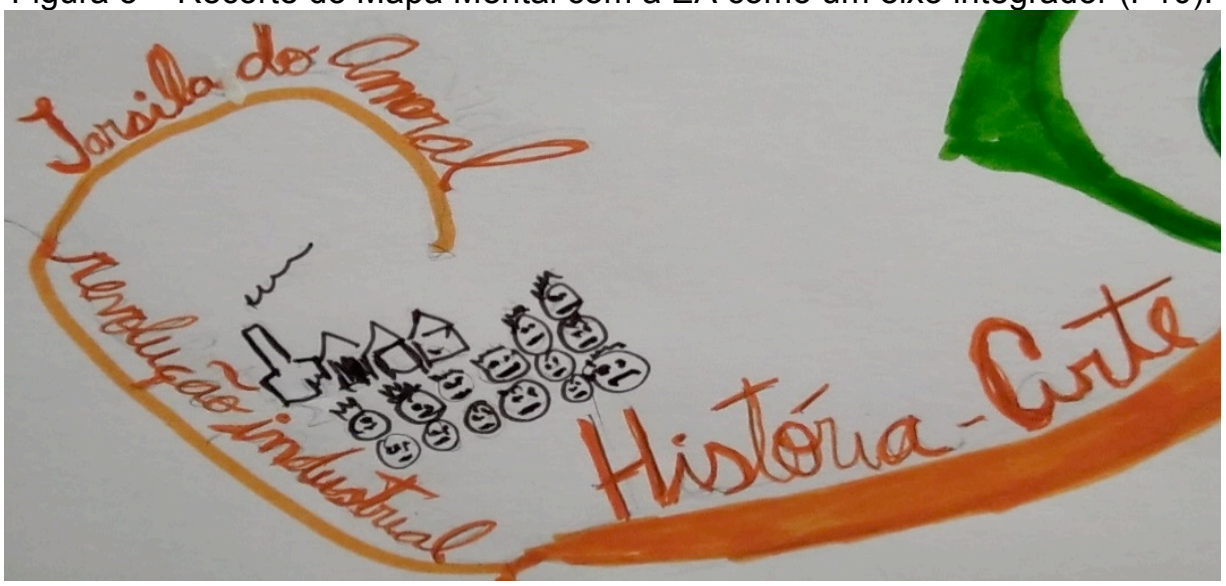

Fonte: Autoras 


\section{RECIMA21 - REVISTA CIENTÍFICA MULTIDISCIPLINAR ISSN 2675-6218}

Nesse recorte P10 desenhou uma representação de um quadro de Tarsila do Amaral, Operários. Essa obra foi pintada em 1933, quando Tarsila do Amaral retornou de uma temporada na antiga União Soviética, onde se envolveu com questões sociais. O quadro representa a diversidade da classe operária, que aumentou conforme a industrialização brasileira se desenvolvia, retratando pessoas que eram oprimidas pela elite da época, como é possível perceber pelo semblante de cada um.

É importante salientar que esta integração representa uma visão do professor sobre o que permeia a sua concepção de interdisciplinaridade. Desta forma, na concepção dos professores P10 e P11 a integração entre as diversas disciplinas do conhecimento é importante, pois assim é possível estar em sintonia para que projetos sejam implementados e discutidos de maneira interdisciplinar, corroborado por Fazenda (2008), e explicitado por P5 no depoimento:

A oficina foi excelente porque agrupou professores de áreas diferentes e proporcionou o trabalho de pesquisa em grupo. Os temas abordados proporcionaram um aprendizado valioso a todos e com certeza esta prática é eficaz no dia a dia corrido do professor. A discussão deste conteúdo fez muita diferença, o trabalho com o Mapa Mental foi a chave de um aprendizado muito importante (P5).

Os professores também argumentaram sobre a importância da inserção da interdisciplinaridade no Plano Político Pedagógico (PPP) da escola, uma vez que esta tem um caráter transversal e interdisciplinar, ou seja, é parte permanente do trabalho escolar. Para os professores, esta necessidade abrange a todos sem distinção, e tem claramente como objetivo mudar o contexto escolar ao inserir uma visão não fragmentada do conhecimento. Para P1, P2 e P4:

\footnotetext{
Conhecer e entender o PPP é importante, pois através dele é possível traçar metas e planejar aulas interdisciplinares mais efetivas e elaboradas (P1)
}

Muito importante para meu aprimoramento profissional. Entender o contexto da interdisciplinaridade e reforçar a importância no PPP (P2).

O Projeto Político Pedagógico trabalha a responsabilidade social e ambiental sendo um norteador para o desenvolvimento dos projetos nas escolas, formando, assim, cidadãos conscientes do seu papel e compromisso com o meio ambiente (P4).

As atividades de discussão sobre a importância do PPP e da Educação Ambiental dentro das ATPC tiveram origem no ano de 2018. Naquele momento, 21 professores (60\% do total) não conheciam o PPP da escola e o restante não sabiam ao certo como a EA estava inserida nesse documento. Após as discussões, os professores, com a anuência da gestão escolar, reivindicaram a inserção da EA no PPP como eixo integrador e permanente (Autora 1).

A oficina foi um fator importante de apoio ao professor, devido as discussões estarem atreladas ao caráter político-pedagógico dos projetos interdisciplinares envolvendo a EA, ao reforçar a concepção de que a escola, de acordo com Mendonça (2007), se compromete com uma mudança quanto as questões ambientais quando envolve o individual e o coletivo. 


\section{RECIMA21 - REVISTA CIENTÍFICA MULTIDISCIPLINAR ISSN 2675-6218}

Esse contexto também está presente nos depoimentos de P7 e P12:

Todo projeto interdisciplinar, sobretudo este, o qual contempla um tema tão importante e com um conteúdo para impactar a consciência ambiental, não apenas dos alunos, mas de toda a equipe escolar no compromisso de, ao conhecer melhor a partir de todo o referencial teórico abordado, possa adotar práticas mais conscientes de consumo e conservação (P7).

A oficina para todas as disciplinas foi muito produtiva e interessante, pois cada professor pode opinar segundo seus conhecimentos, e assim somou-se à nossa compreensão sobre vários aspectos à Educação Ambiental (P12).

Esses depoimentos de P7 e P12 reforçam as opiniões de Lindner (2012), Guimarães (2011) e Tristão (2012) sobre a importância da articulação entre a EA e a interdisciplinaridade para romper com a fragmentação do conhecimento de um ensino compartimentalizado.

Quando P12 argumentou que o professor pode, dentro dos seus conhecimentos, compor com seus pares e assim compreender melhor a EA, mostra o quanto a equipe deve estar engajada em discussões que não causem constrangimentos e que cada um deve respeitar a opinião do outro. Isso mostra o nível que a formação continuada pode atingir desde que seja planejada e que os participantes incorporem esta ideia. Para González-Gaudiano (2006), isto reflete o porquê considerar a interdisciplinaridade como a melhor estratégia de articulação com o meio ambiente e a sustentabilidade devido à integração dos diferentes campos disciplinares e as suas interações.

Alguns problemas que a escola atualmente enfrenta para desenvolver projetos interdisciplinares de acordo com P13 é a questão financeira e o tempo, como pode ser observado no seu depoimento:

São projetos importantes no qual há vontade de se fazer, mas esbarra às vezes na parte financeira e no espaço a ser ocupado. O tempo também conta como fator negativo (P13).

Ao buscar a interdisciplinaridade e a formação continuada em ambientes escolares, o professor pode buscar caminhos com seus pares para enfrentar os problemas que muitas vezes tem sua origem em um planejamento que ocorre fora do ambiente escolar, em secretarias da educação que estão longe de conhecer os problemas e as dificuldades que afligem a equipe escolar.

\section{CONSIDERAÇÕES FINAIS}

Nesse artigo apresentamos o resultado de uma pesquisa que partiu da indagação: os mapas mentais podem ser utilizados como ferramenta de análise da compreensão dos professores sobre a temática desenvolvida na oficina? Os resultados observados evidenciaram que eles podem não só serem utilizados para a análise de compreensão de um determinado 

ISSN 2675-6218

tema, no nosso caso, a interdisciplinaridade e os projetos interdisciplinares na Educação Ambiental, mas também a sua construção proporcionou um novo subsídio para os professores utilizarem em suas aulas ou mesmo para estudarem. Os mapas mentais auxiliaram na visão sistêmica da interdisciplinaridade e no desenvolvimento da habilidade de abstração, uma vez que para sua construção retiraram do texto as ideias principais e as colocaram na forma de palavraschave. Além disso, o uso de mapas mentais quebrou o formato tradicional que em geral as ATPC apresentam.

\section{REFERÊNCIAS}

BEHRENS, M. A. Projetos de aprendizagem colaborativa num paradigma emergente. In.: MORAN, J. M. et al. Novas tecnologias e mediação pedagógica. 10. ed. Campinas: Papirus, 2006.

BOGDAN, R. C.; BIKLEN, S. K. Investigação qualitativa em educação: uma introdução à teoria e aos métodos. Porto (Portugal): Porto Editora, 2010.

BRASIL. Parâmetros Curriculares Nacionais: Ensino Médio. Brasília: MEC, 2000.

BRASIL. PCN + Ensino Médio: Orientações educacionais complementares aos Parâmetros Curriculares Nacionais. Ciências humanas e suas tecnologias. Brasília: Ministério da Educação, 2002.

BRASIL. Ministério da Educação. Planejando a próxima década conhecendo as 20 metas do Plano Nacional de Educação. Secretaria de Articulação com os Sistemas de Ensino (MEC/ SASE), 2014.

BRASIL. Ministério da Educação. Ministério da Educação parabeniza mulheres neste 8 de março. Brasília: MEC, 2021. Disponível em: https://www.gov.br/mec/ptbr/assuntos/noticias/ministerio-da-educacao-parabeniza-mulheres-neste-8-de-marco. Acesso em: 11 maio. 2021.

BUZAN, T. Dominando as técnicas de mapas mentais. São Paulo: Ed. Cultrix. 2019.

EVANGELISTA, I. A. S.; COLARES, M. L. I. S.; FERREIRA, M. A. V. Projetos Educativos Interdisciplinares na prática docente. In.: CONGRESSO NACIONAL DE EDUCAÇÃO - IX EDUCERE, 9., 2009, Curitiba-PR. Anais [...] Curitiba-PR: PUCPR, 2009. p.1-12.

FAZENDA, I. C. A. A aquisição de uma formação interdisciplinar de professores. In.: FAZENDA, I. C. Didática e interdisciplinaridade. 13. ed. Campinas: Papirus, 2008.

GONZÁLEZ-GAUDIANO, E. Interdisciplinaridade e educação ambiental: explorando novos territórios epistêmicos. In.: SATO, M., CARVALHO, I. (Orgs.). Educação Ambiental: pesquisa e desafios. Porto Alegre: Artmed, 2006. p. 119-133.

HERMANN, W.; BOVO, V. Mapas Mentais enriquecendo inteligências: captação, seleção, organização, síntese, criação e gerenciamento de informação. Campinas: [S.e.], 2005.

HERNÁNDEZ, F. Transgressão e mudança na educação: os projetos de trabalho. Porto Alegre: Artmed, 2010. 


\section{RECIMA21 - REVISTA CIENTÍFICA MULTIDISCIPLINAR ISSN 2675-6218}

O MAPA MENTAL COMO FERRAMENTA DE ANÁLISE DA COMPREENSÃO DE PROFESSORES SOBRE INTERDISCIPLINARIDADE Terezinha Marisa Ribeiro de Oliveira, Carmem Lúcia Costa Amaral

HUBERMAN, M. O ciclo de vida profissional dos professores. In.: NÓVOA, A. Vidas de professores. Portugal: Editora LDA, 2013.

KEIDANN, G. L. Utilização de Mapas Mentais na Inclusão Digital. In.: Educom Sul- Educomunição e Direitos Humanos, 2, 2013, Rio grande do Sul. Anais [...]. Rio Grande do Sul, 2013. Disponível em: http://coral.ufsm.br/educomsul/2013/com/gt3/7.pdf. Acesso em: 01 fev. 2021.

LINDNER, E. L. Refletindo sobre o ambiente. In.: LISBOA et al. Educação Ambiental: da teoria à prática. Porto Alegre: Mediação, 2012, p. 13-19.

LUQUETTI, E. C. F.; SOUZA, S. M. F. O ensino da língua inglesa na perspectiva interdisciplinar. InterSciencePlace - Revista Científica Internacional, v. 11, n. 04, p. 133 a 194, 2016.

MENDONÇA, P. R. Políticas de formação continuada de professores e professoras em educação ambiental no Ministério da Educação. In: RACHEL, S. S. (Coord.). Vamos cuidar do Brasil: conceitos e práticas em educação ambiental na escola. Brasília: Ministério da Educação. UNESCO, 2007. Disponível em: http://portal.mec.gov.br/dmdocuments/publicacao3.pdf. Acesso em: 02 Mar. 2021.

TRISTÃO, M. As dimensões e os desafios da educação ambiental na contemporaneidade. In.: RUSCHEINSKY, A. (org.). Educação Ambiental: abordagens múltiplas. Porto Alegre: Penso, 2012. p. 233-249.

VILELA, V. V. Modelos e métodos para usar mapas mentais: usos detalhados de Mapas Mentais para seu cotidiano, seu aprendizado e suas realizações. 5. ed. Brasília: Edição do Autor, 2012.

ZIDAN, V. M. L. Interdisciplinaridade: um olhar sobre sua prática na Educação Básica. Recôncavo: Revista de História da UNIABEU, v. 1, n. 2, p.98-111, 2012.

ZANDOMENEGHI, A. L. A. O.; GOBBO, A.; BONFIGLIO, S. U. A utilização do mapa mental como ferramenta facilitadora no desenvolvimento da habilidade da escrita. Revista Educação e Emancipação, v. 8, n. 1, p. 11- 48, 2015. 